International Journal of Natural Science and Reviews
(ISSN:2576-5086)

\title{
Ancient extinct life forms fossilized through volcanism in sedimented rivers and other plains of Mars
}

\section{Florent Pirot}

Independent researcher

\begin{abstract}
The use of rules laid in earlier articles of the author allows to isolate the remains of life forms on Mars. All of these life forms have perished in volcanic eruptions. Pyroclastic flows, mudslides and the lava fill-up of underwater caves are shown to have killed by surprise the animals. The violence of the event allows conservation of the remains, as the covering by tuf, lava, hot mud, allows the casting of rock molds. An early observation of a femur in 2014 was discarded as result of erosion. This finding comes together with a skull cast in stone. It is indeed a skull and a femur - this can be validated ex-post by crossing with the findings of the author in an earlier article and these new ones.
\end{abstract} ${ }^{*}$ Correspondence to Author: Florent Pirot

Independent researcher

How to cite this article:

Florent Pirot. Ancient extinct life forms fossilized through volcanism in sedimented rivers and other plains of Mars. International Journal of Natural Science and Reviews, $2021 ; 6: 18$.

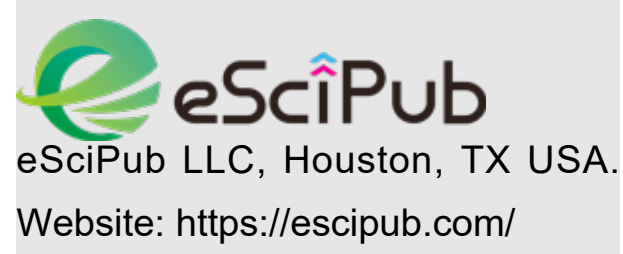




\section{Details of the findings :}

The first picture that attracted the author's attention is reproduced below - recent NASA Perseverance image around Van Zyl Overlook.

The application of the rules laid in [1] led to an immediate theorization of a pyroclastic flow on a river with Gobiidae (two big individuals on the bottom part of the image above). A small crocodilian is also visible to the bottom right (zoom in next image). The pyroclastic flow would have cast them as Pompeii-like remains, with later dispersion of the mass of ashes but inbetween fill up of the holes let by the burn of the organic matter with tuf and water (naturally doing the work the archaeologists did in Pompeii by filling with cement).
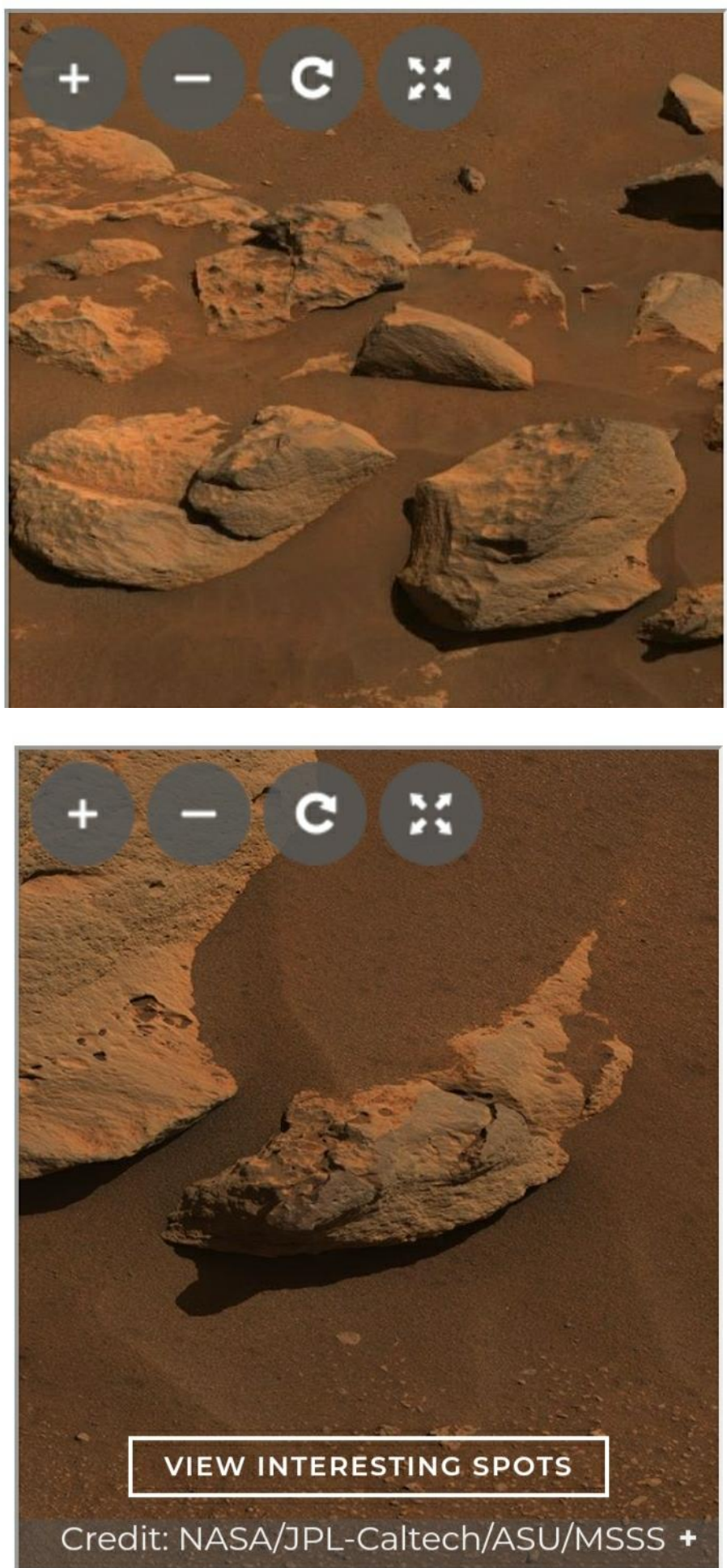

Mastcam-Z's 360-degree View of "Van Zyl Overlook": NASA's 
The axolotl face on the top middle-to-left of the first picture leads to another interesting hypothesis with an underground cave partly or entirely filled with water, that eventually became taken in a phreatomagmatic eruption. In a pattern already described in [1] with the shockwaves and transfer of shapes in a magmatic chamber, the shapes are transferred above the cave. This second hypothesis is favoured by the author because the longstanding hypothesis on life on Mars relies mostly on underground caves with water.

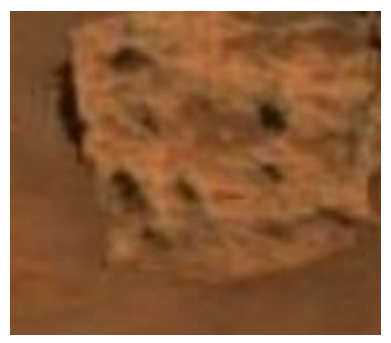

Illustration 1: The axolotl transfered up by the underground explosive magmatism shockwaves from the water cave - or possibly by a pyroclastic flow coming from the left.

Another animal was identificated in another recent image from Perseverance :
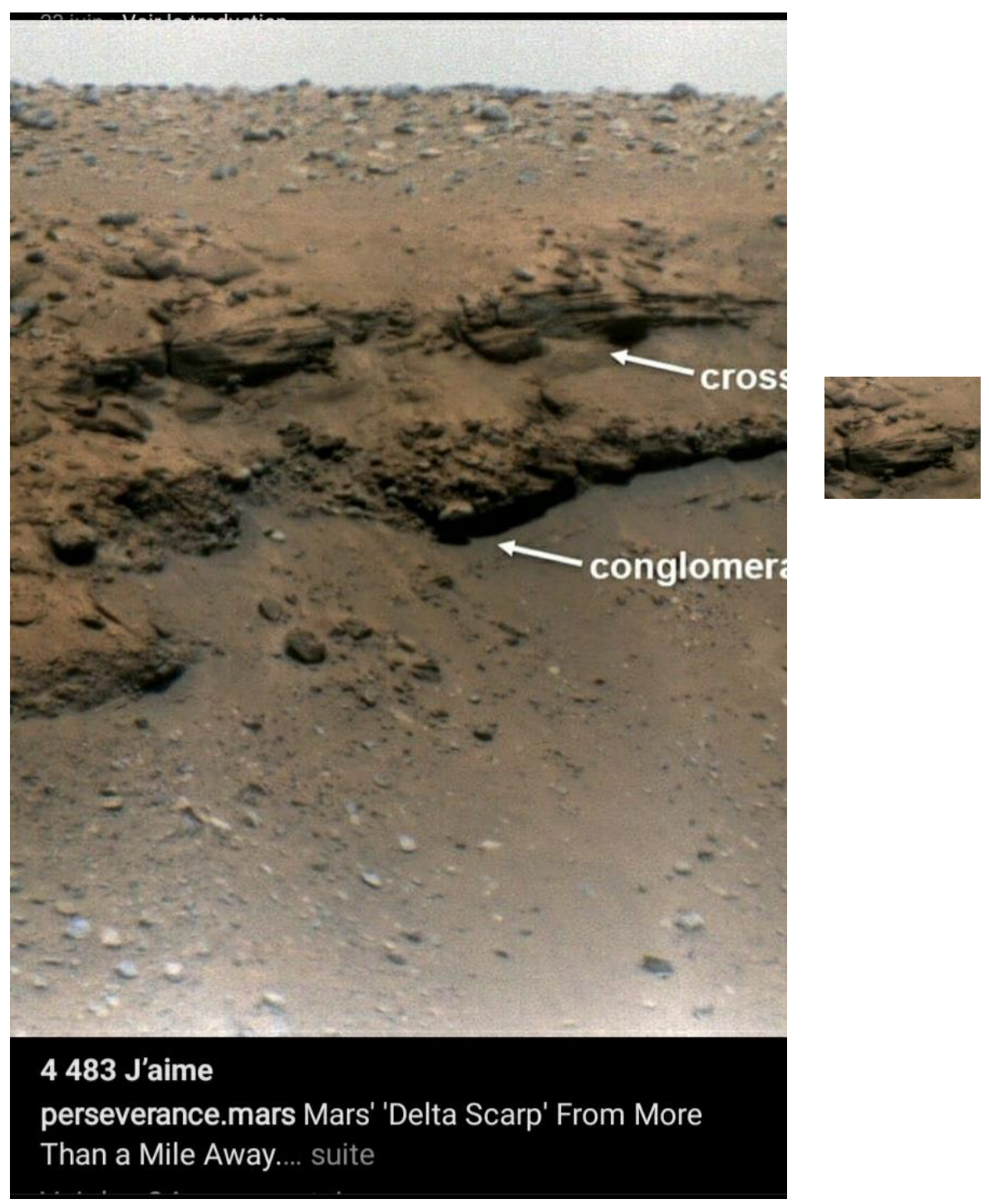
There is an hippopotamus-like animal also cast in stone on the left of the image, hanging out. It seems to have been taken in the magma by dying above the bottom of a subduction trench and was taken in the subduction process, remeerging with the imprint transfer phenomenon described in [1] later. Another baby hippopotamus-like animal appears just above the top white arrow.

These animals show a life existing mainly in rivers and water environments. It also allows discarding the argument on the femur from " erosion " - in the 2014 image case - a skull is also clear to the right of the femur in that famous image (in annex after references). An herbivorous animal taken in a volcanic mudslide is the main hypothesis. The mudslide kept the shape of the animal, after the organic matter disappears the solid holes are filled with some tephra and water that slowly consolidates a cast of this material. Then the mud is blown away by erosion and winds and the cast falls down. A maiopatagium-like animal is suggested. The nose shows herbivorous temperament. Finding cenozoic-like animals on the outer layers of Mars is a relatively unsurprising constatation relatable to the more active magmatism at these times that allowed correct temperatures in spite of the higher distance to the Sun. Living near volcanoes was essential for these last groups of living animals to find living temperatures but volcanoes also were the reason for their usual death.

The following image shows a beetle-like superinsect fossilized as stone, possibly having eaten itself too much faeces, it lived upon it, gained a particular gaze from the hormones captured in the faeces it lived upon. The faeces were extremely hot and the superinsect itself died from the hotness of the meal. Or, more likely, was killed by a short but rapid flow of very liquid lava (similar to Ol Doinyo Lengai lava in its fluidity) descending from right to left, that descended from a geologically mostly underground volcanic chamber with still quite a lot of hydratation, and covered it with a thin veil after killing it from behind. The animal had indeed stayed behind a rush of animals that had felt a volcanic eruption was coming, was very excited to feed on the remains, and was too busy to see the catastrophe coming.

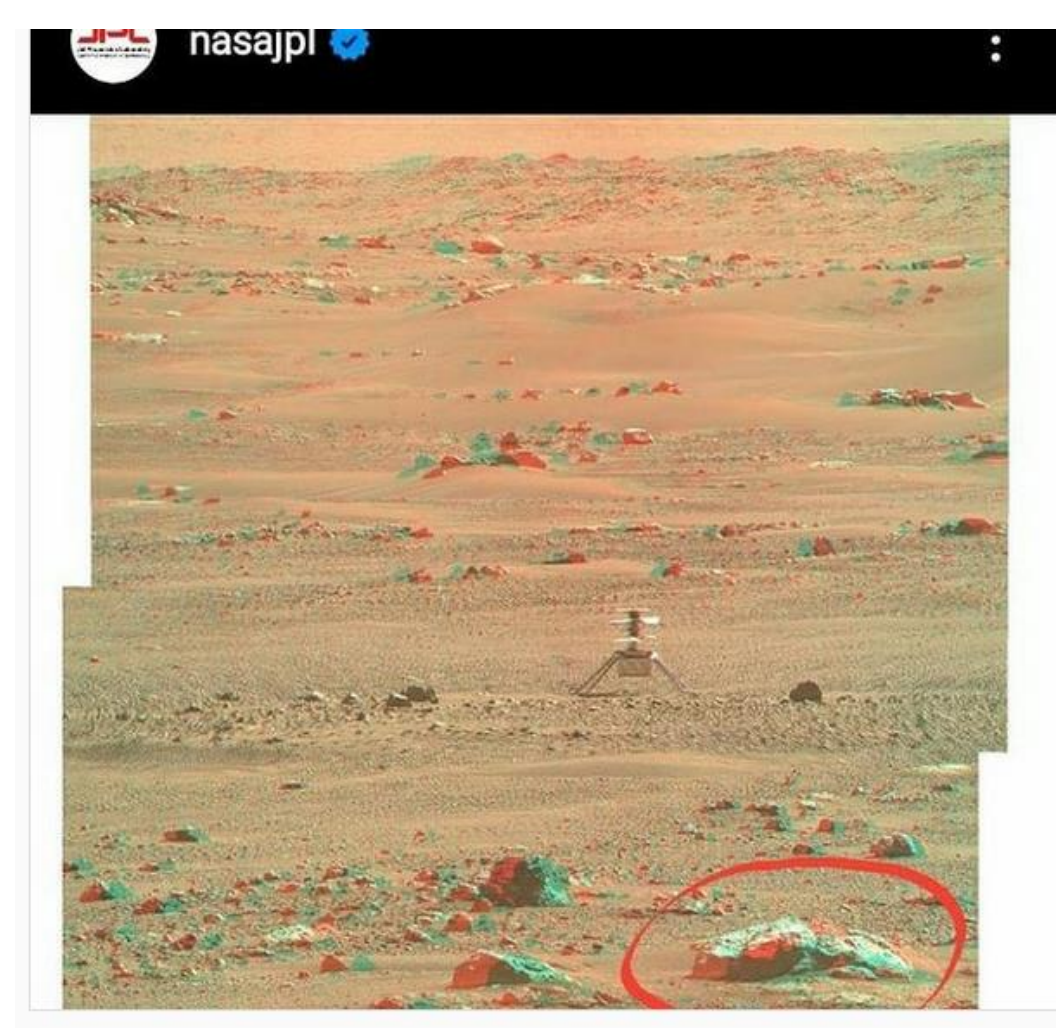




\section{Discussion}

There is no reason to believe there would not be other such creatures taken in stone by the volcanic eruption through processes described typically in ${ }^{[1]}$.

The creatures exhibit signs of similarity with what is found on Earth. This could be surprising but may in fact be explained by the fact that there are not an infinity of developmental patterns, for DNA. The Bose-Einstein condensation in basalt with protons brought by volcanism (from ternary fission products) was suggested to be the key founder for the random, extremely rare event of the actual apparition of an independent form of life in ${ }^{[2]}$. Another published article has suggested that fission in early magmatism has left visible remains on DNA structure (that cannot be reproduced experimentally at a low temperature and hence demonstrating the paleo-conditions with higher temperatures near volcanic thermalism that are the main theorem and that is also involved in ${ }^{[2]}$ ), confirming that above suggestion ${ }^{[3] 1}$. The shape of animals adapt to the surrounding realms and natural selection certainly provides for the emergence of a limited number of designs (jaws, feet, skin etc.) adapted for these environment ; harmonic oscillations on a long period (see ${ }^{[2]}$ ) lead to the usual reproduction of such shapes, in homotethy, on the various planets where such a phenomenon happens, what makes the difference is the distance to the central star and Mars shows that compensating by volcanic heat did not maintain life in a sustained way.

\section{References :}

1. Florent Pirot. 'Paleontology vs. Archaeology in the French Riviera volcanism : crystallized Permian animals and dinosaur skeletons in andesitic rocks, and human remains from the medieval times'.
International Journal of Archaeological Research, 2021, 2:7. DOI: 10.28933/ijahr-2021-05-0105

2. Florent Pirot. 'Fissile vs. Fertile Atoms Renamed Squeezed State vs. Anti-squeezed States, Why Uranium, Thorium Etc are Invisible in Star Spectrometry Data, and a Return on Human Behaviour, Cultural Insecurity Defined as Antisqueezed Behaviour, Linked to Brain Trauma.' International Journal of Physics 8, no. 3 (2020): 108-113.

3. Ewald Hejl, 'Are fission tracks in enantiomorphic minerals a key to the emergence of homochirality?' Neues Jahrbuch für Mineralogie Abhandlungen Band 194 Heft 1 (2017), p. 97 106, Jan 1, 2017 DOI: 10.1127/njma/2017/0049

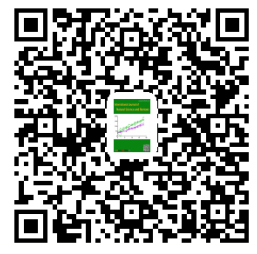

1 Thanks to Richard F. Cronin for providing me this extraordinary reference 
Florent Pirot, IJNSR, 2021; 6:18

Annex :

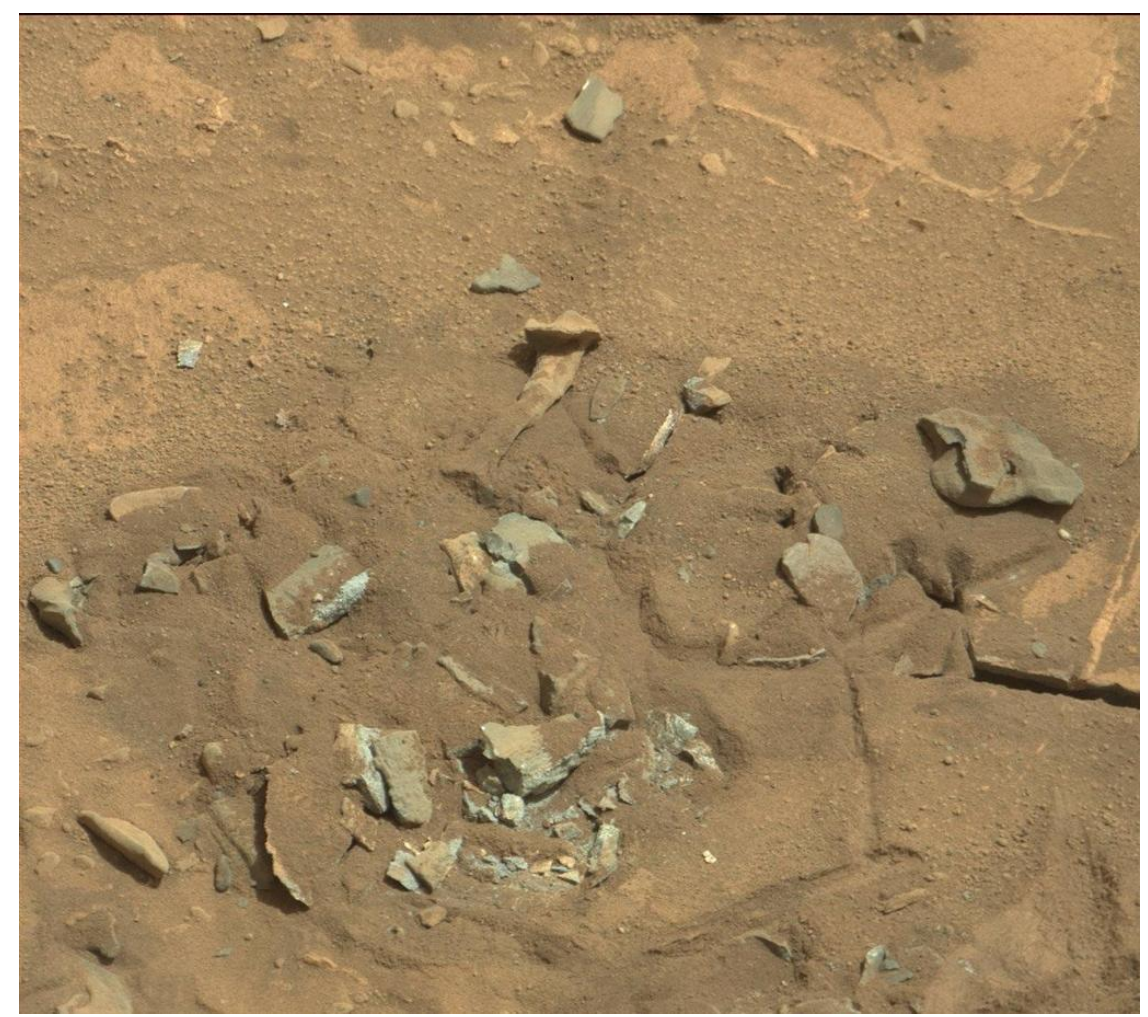

Source https://www.space.com/26922-thigh-bone-on-mars-rock-photo.html 